\title{
HistOCHEMICAL AND IMMUNOHISTOCHEMICAL CHARACTERISTICS OF ELASTOFIBROMAS
}

\author{
Funda Tasli ${ }^{1,2}$, Enver Vardar ${ }^{1}$, Asuman Argon ${ }^{1}$, Tulu Kabat ${ }^{1}$, Senem Deniz ${ }^{1}$, Ahmet Nart $^{3}$, \\ YAVUZ KeCECI ${ }^{4}$
}

${ }^{1}$ Department of Pathology, Bozyaka Training and Research Hospital, Izmir, Turkey

${ }^{2}$ Department of Pathology, Faculty of Medicine, Sifa University, Izmir, Turkey

${ }^{3}$ Department of General Surgery, Faculty of Medicine, Sifa University, Izmir, Turkey

${ }^{4}$ Department of Plastic and Reconstructive Surgery, Bozyaka Training and Research Hospital, Izmir, Turkey

\begin{abstract}
Elastofibromas are slow-growing and rare soft-tissue tumors. The etiology and pathogenetic mechanisms are still controversial and there are only a few studies in the literature investigating the histochemical, immunohistochemical, and genetic features to determine the pathogenesis.

We investigated the cellular composition of lesions with a diagnosis of elastofibroma in 17 patients by using histochemical and immunohistochemical methods.

There were 17 cases with a mean age of 53.5 years. Mean lesion diameter was $6.6 \mathrm{~cm}$. The immunohistochemical method showed vimentin and factor XIIIa positivity in all cases. Four cases had focal myoglobin positivity in the spindle-shaped cells between the collagen fibers. Spindle cells were positive for CD34 in 8 cases. Smooth muscle actin, desmin, type 4 collagen and laminin were negative in all cases. The elastic nature of the abnormal fibers was shown histoch with Verhoeff elastin staining and aldehyde fuchsin staining in all cases.

Our results have shown that the concurrent positivity of factor XIIIa and CD34 in the cells forming the lesion might show that the lesionoriginates from primitive dermal mesenchymal cells. In addition, the myoglobin positivity found in some cases indicates the possibility of a myofibroblastic origin of elastofibromas.
\end{abstract}

Key words: elastofibroma, immunohistochemistry, CD34, factor XIIIa.

\section{Introduction}

Elastofibromas are rare, benign, slow-growing soft tissue tumors and were first described in 1961 by Jarven and Saxi $[1,2]$. They are characteristically located in the distal scapular region [3-5]. They are usually seen in middle-aged and elderly individuals [6]. Morphologically, there is dense collagen mixed with globular or droplet type abnormal elastic fibers as well as a normal fatty tissue component $[6,7]$. The real etiology and pathogenetic mechanisms of elastofibromas are still controversial. There are only a few studies in the literature investigating the histochem- ical, immunohistochemical, and genetic features to determine the pathogenesis [8].

We investigated the cellular composition of 17 elastofibroma lesions using histochemical and immunohistochemical methods in this study and discuss the clinicopathological data of the cases in comparison with the literature.

\section{Material and methods}

A total of 17 cases diagnosed with elastofibroma at the Ministry of Health, Izmir Bozyaka Training and Research Hospital's Department of Pathology between the years of 2000 and 2012 were retro- 
spectively analyzed in this study. Clinical data such as age, gender, and location of the lesion were taken from the medical records of the cases. Four-micron thick sections were taken from the tissues that were fixed with $10 \%$ formalin and embedded in paraffin. The sections were then deparaffinized and stained with hematoxylin and eosin. Histochemical and immunohistochemical methods were also applied to the sections to determine the cellular components. Histochemically, Masson trichrome, Verhoeff elastin stain, Giemsa, toluidine blue and aldehyde fuchsin-alcian blue stains; immunohistochemically, smooth muscle actin (1A4, 1/200, Spring Bioscience), desmin (D33, 1/50, Thermo Scientific), myoglobin (MGN01, 1/200, Spring Bioscience), CD34 (QBEND/10, 1/200, Thermo Scientific), vimentin (SP20, 1/200, Spring Bioscience), type 4 collagen (CIV22, 1/50, Dako Cytomation, Denmark), laminin (polyclonal rabbit, Biogenex), and factor XIIIa (AC-1A1, 1/100, Thermo Scientific) antibodies were applied to the lesions.

\section{Results}

\section{Clinical data}

The mean age of the 17 patients was 53.5 years (oldest 73, youngest 28 years). There were $13 \mathrm{fe}$ males and 4 males. All lesions were located in the dorsal scapular region. All patients underwent surgical resection. Complete resection was performed in 16 patients while one case with incomplete resection underwent a re-excision 2 months later. None of the cases suffered a recurrence.

\section{Macroscopic findings}

All lesions had grayish-white surface areas with irregular contours mixed with fatty tissue areas. The mean diameter of the tumors was $6.6 \mathrm{~cm}$.

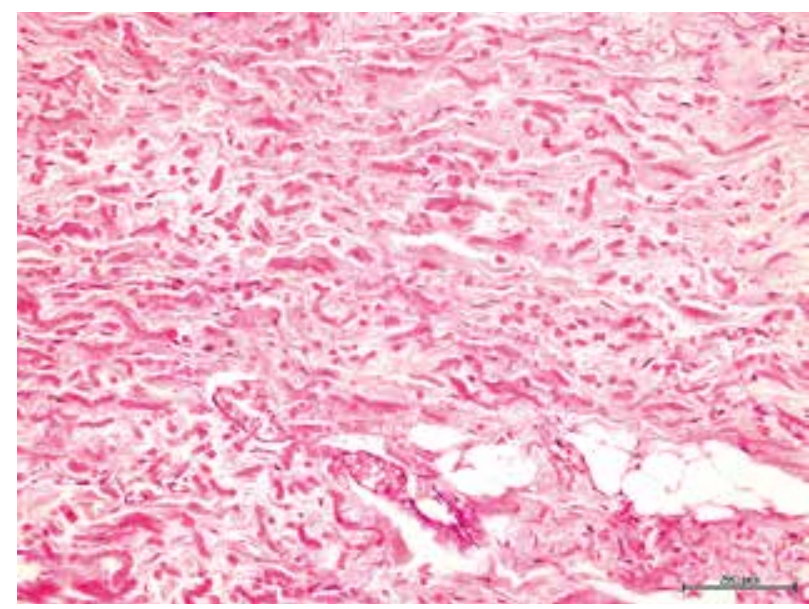

Fig. 1. Abnormal elastic fibers in fibrocollagenous stroma with spindle or stellate cells (HE, magnification $200 \times$ )

\section{Microscopic findings}

The lesion was composed of a variable amount of mature adipose tissue with spindle-like and satellite collagen bands together with abnormal elastic fibers embedded in this fibrocollagenous matrix under light microscopic examination (Fig. 1). Elongated or droplike abnormal elastic fibers were observed.

\section{Histochemical findings}

The elastic nature of the abnormal fiber was shown histochemically with Verhoeff elastin staining and aldehyde fuchsin staining in all cases (Fig. 2). Collagen bands in the lesion were determined with Masson trichrome staining. In addition, the presence of mast cells was shown with toluidine blue and Giemsa staining.

\section{Immunohistochemical findings}

Diffuse positivity was found with vimentin and factor XIIIa in all cases (Figs. 3, 4). Four cases had focal myoglobin positivity in the spindle-shaped cells between the collagen fibers (Fig. 5). Spindle cells were found to be CD34-positive in 8 cases (Fig. 6). Smooth muscle actin, desmin, type 4 collagen and laminin were negative in all cases.

\section{Discussion}

Although elastofibromas are well defined in terms of clinical data, treatment approach and histopathological diagnostic criteria, the pathogenetic mechanisms and their real nature are still controversial.

Electron microscopic findings of elastofibromas in previous studies report the spindle cells in the lesion to be fibroblastic or myofibroblastic in nature [9-11]. Elastofibromas are believed to be a reactive process caused by microtraumas [11]. Taking this into account, Ramos et al. [9] postulate elastofibromas to

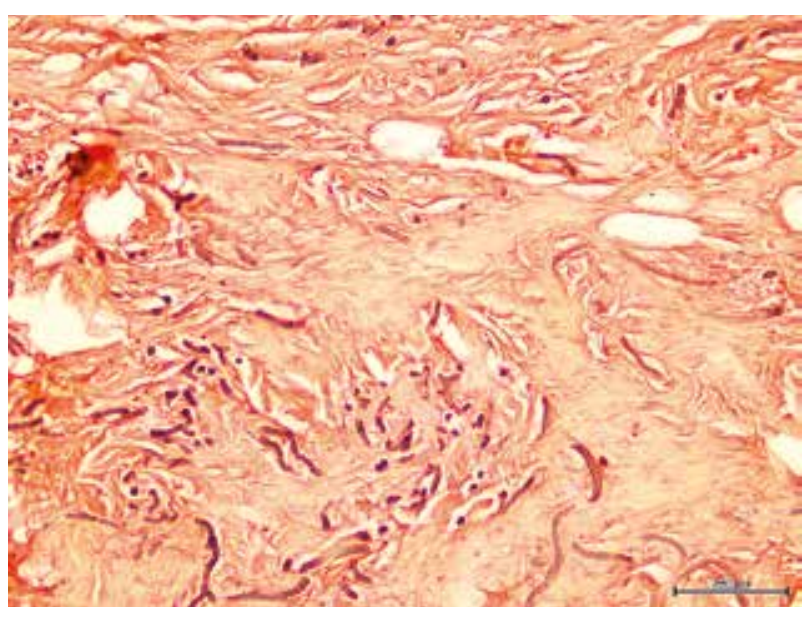

Fig. 2. Elongated and globular elastic fibers are seen. (Verhoeff Elastin Stain, magnification $200 \times$ ) 


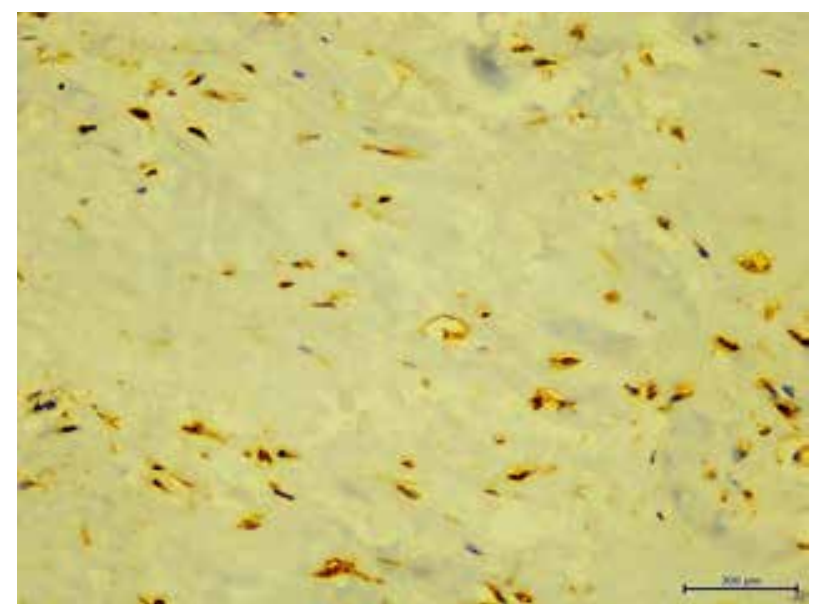

Fig. 3. Vimentin was diffuselly positive in spindle-shaped cells (vimentin, magnification $400 \times$ )

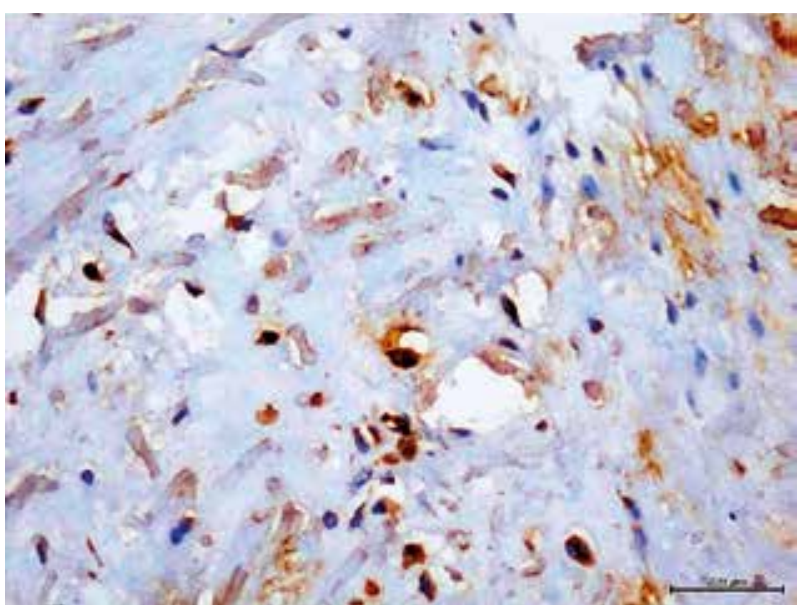

Fig. 5. Focal positive immunostaining by myoglobin in elastofibroma (myoglobin, magnification $400 \times$ )

be possibly of myofibroblastic origin as the main cell components in reactive processes are myofibroblasts. Ruelas $e t$ al. found actin and desmin positivity in all 4 of their cases as the evidence of a myofibroblastic nature [12]. Spindle cells were actin and desmin negative in our series but the myoglobin positivity in 4 cases may indicate possible myofibroblastic differentiation, similar to the findings of Ruelas $e t$ al.

Later studies have made a possible myofibroblastic nature controversial. Hisaoka et al. analyzed 14 elastofibroma cases and reported that they could not find, in any case, stress fibers or a cell-stroma connecting region (fibronexus), which are ultrastructural evidence of myofibroblastic differentiation [6]. The same investigators also could not find positivity with actin and desmin and reported that the previously described myofibroblastic differentiation was not seen in their lesions [6]. Similar to Hisaoka et al., there are other publications defining actin and desmin negativity in elastofibromas and reporting them to be of fibroblastic nature and not myofibroblastic $[4,5,8,13]$.

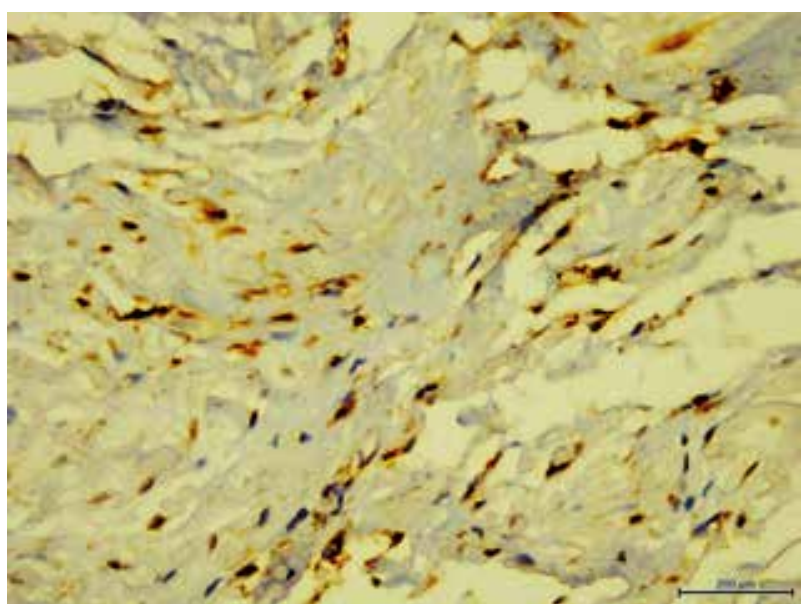

Fig. 4. Diffuse positive factor XIIIa immunostaining in elastofibroma (factor XIIIa, magnification $400 \times$ )

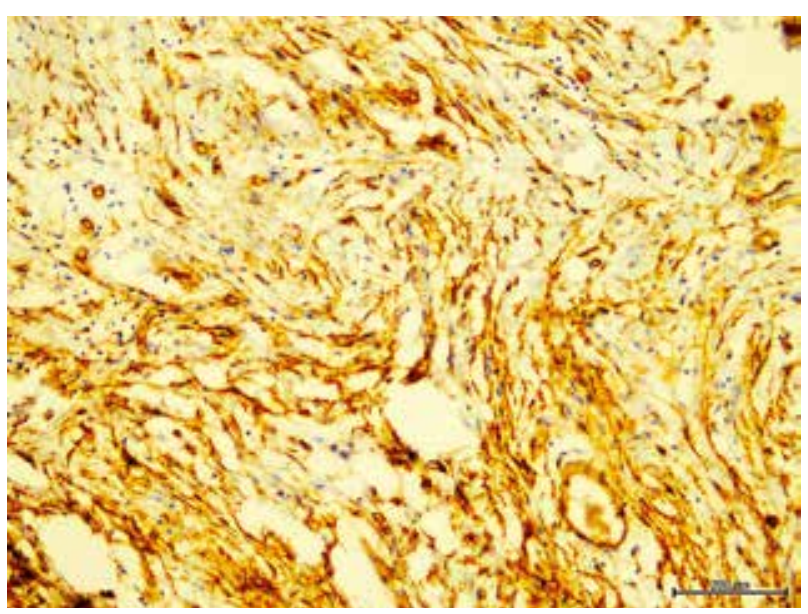

Fig. 6. CD34 was expressed in spindle-shaped cells (CD34, magnification $400 \times$ )

Elastofibromas are very commonly located in the interscapular region and some authors therefore believe these lesions to be a reactive process stemming from degeneration in connective tissues caused by the constant friction of the shoulder on the ribcage with repetitive movements [5, $7,10,14]$. However, there are studies that report the lesion to be more neoplastic than reactive by demonstrating chromosomal instability and clonal chromosomal aberrations as evidence $[6,15,16]$. Chromosomal studies were not performed in our cases but none of the patients reported recurrent severe physical activity supporting a reactive process in the anamnesis.

The possibility of genetic inheritance in the pathogenesis of elastofibromas has also been discussed. The ABCC6 gene, previously described in pseudoxanthoma elasticum cases [17], was investigated in four elastofibroma cases in another study but could not be detected [7]. However, Nagamine et al. reported a positive family history in $1 / 3$ of the cases in a series 
of 170 patients in another study investigating possible genetic inheritance [18]. None of our cases had a positive family history.

A large number of studies in the literature have defined diffuse CD34 positivity in spindle-shaped stromal cells $[4,6,8]$. CD 34 positivity was observed in 8 of our cases, in accordance with the literature.

An interesting immunohistochemical finding in the present study is the factor XIIIa positivity in all cases. Only a few studies have investigated factor XIIIa positivity in elastofibromas. Yamazaki et al. reported factor XIIIa positivity in all 5 of their cases, similar to our study [19]. Narvaez et al. defined 2 dendritic cell-type in the dermis: a CD34 (-) and factor XIIIa-positive [20]. Silverman and Tamsen reported the CD34 and factor XIIIa (+) cells to be primitive mesenchymal cells and to be present together in some dermal tumors, but they did not define this association in elastofibromas [21]. This association was found in approximately half of the cases in our series, and is considered to be a finding supporting a primitive mesenchymal origin of the cells making up the elastofibroma.

Gray et al. investigated the relationship between Kaposi sarcoma spindle cells and dermal dendrocytes and reported the number of factor XIIIa $(+)$ cells to be high in plaque and patchy stage tumors and decreasing in nodular stage tumors, whereas the CD34-positive spindle cells differentiating towards endothelium increased in the nodular stage [22]. According to Silverman, these findings of Gray et al. indicate that factor XIIIa-positive cells cause clonal CD34-positive cell proliferation [21]. This speculation may also be valid for elastofibroma pathogenesis and the CD34 $(+)$ cells detected in elastofibromas may be spindle cells that are differentiated in the fibroblastic or myofibroblastic direction following activation by factor $13 \mathrm{a}(+)$ dermal dendrocytes. The presence of CD34 (+) in all 4 of our patients with focal myoglobin positivity may indicate the possibility of myofibroblastic differentiation in primitive mesenchymal cells.

Mast cells are normally located in the dermis and are active in fibroblast stimulation with some cytokines present in their granules, and also serve in the reconstruction of extracellular matrix in wound healing with the proteases they contain [23]. There are also publications that report mast cells to secrete fibroblast growth factor [24]. A study examining 7 elastofibroma cases showed the presence of mast cells in 5 of them [4]. We found the presence of varying amounts of mast cells with toluidine blue and $\mathrm{Gi}$ emsa histochemical staining in 10 of our 17 cases, in accordance with the literature. The presence of mast cells in elastofibroma cases may be responsible for the fibroblastic proliferation of the lesion.
In conclusion, our findings of $\mathrm{CD} 34$ and vimentin positivity with actin and desmin negativity support the fibroblastic nature of the lesion, and the positivity of factor XIIIa associated with CD34 is interpreted as evidence of the lesion being derived from dermal mesenchymal cells. However, determination of myoglobin positivity in some cases with $\mathrm{CD} 34(+)$ positivity made us consider that CD34 (+) mesenchymal cells could be differentiated in the myofibroblastic direction. Therefore, the possibility of a myofibroblastic origin of the lesion could not be completely excluded. Immunohistochemical studies in larger series may provide more accurate information on the cellular composition of elastofibromas.

The authors declare no conflict of interest.

\section{References}

1. Nishio J, Isayama T, Iwasaki H, Naito M. Elastofibroma dorsi: diagnostic and therapeutic algorithm. J Shoulder Elbow Surg 2012; 21: 77-81.

2. Yáñez S, Val-Bernal JF, Echevarría MA, Landeras R, Izquierdo J, Gallardo E. Retrospective analysis of 6 cases of elastofibroma dorsi. Actas Dermosifiliogr 2008; 99: 644-647.

3. Muratori F, Esposito M, Rosa F, Liuzza F, Magarelli N, Rossi B, Folath HM, Pacelli F, Maccauro G. Elastofibroma dorsi: 8 case reports and a literature review. J Orthop Traumatol 2008; 9: 33-37.

4. Banu Dogan Gun, Burak Bahadır, Kemal Behzatoğlu, Mustafa Özkan Gün, Şükrü Oğuz Özdamar. Elastofibroma: a clinicopathologic and immunohistochemical study of seven cases and literatüre review. APMIS 2007; 115: 115-119.

5. Neri A, Caruso S, Bettarini F, Falzarano SM, Di Martino M, Vuolo G, Pedrazzani C, Marrelli D, Roviello F. Elastofibroma dorsi: three cases of personal experience. G Chir 2009; 30: 96-99.

6. Hisaoka M, Hashimoto H. Elastofibroma: clonal fibrous proliferation with predominant CD34-positive cells. Virchows Arch 2006; 448: 195-199.

7. Naouri M, Michenet P, Chassaing N, Martin L. Immunohistochemical characterization of elastofibroma and exclusion of ABCC6 as a predisposing gene. Br J Dermatol 2007; 156: 755-758.

8. Kuroda N, Hamaguchi N, Ohara M, Hirouchi T, Mizuno K, Hayashi Y, Lee GH. Elastofibroma: a histochemical, immunohistochemical, and ultrastructural study of two patients. Med Mol Morphol 2008; 41: 179-182.

9. Ramos CV, Gillespie W, Narconis RJ. Elastofibroma. A pseudotumor of myofibroblasts. Arch Pathol Lab Med 1978; 102: 538-540.

10. Christopher DM Fletcher, K. Krishnan Unni, Fredrik Mertens. WHO Pathology \& Genetics Tumors of Soft Tissue and Bone. IARC Press, Lyon 2002.

11. Franz M. Enzinger, Sharon W. Wiess. Soft Tissue Tumors. Third Edition. Mosby-Year Book, Inc.1995.

12. Ruelas Villavicencio AL, Aponte Paredes PS, Ortiz Hidalgo C. CD-34 expression in elastofibroma. Clinicopathological, histochemical, and immunohistochemical study of four cases. Rev Invest Clin 1999; 51: 11-16.

13. Kayaselçuk F, Demirhan B, Kayaselçuk U, Ozerdem OR, Tuncer I. Vimentin, smooth muscle actin, desmin, S-100 protein, p53, and estrogen receptor expression in elastofibroma and nodular fasciitis. Ann Diagn Pathol 2002; 6: 94-99. 
14. Marcos J, Rodríguez Russo P, Lima S, Rodríguez EL. Elastofibroma dorsi: an unusual case of a subscapular nodular mass. J Clin Rheumatol 2004; 10: 21-24.

15. Vanni R, Marras S, Faa G, Uccheddu A, Dal Cin P, Sciot R, Samson I, Van den Berghe H. Chromosome instability in elastofibroma. Cancer Genet Cytogenet 1999; 111: 182-183.

16. Batstone P, Forsyth L, Goodlad J. Clonal chromosome aberrations secondary to chromosome instability in an elastofibroma. Cancer Genetics and Cytogenetics 2001; 128: 46-47.

17. Chassaing N, Martin L, Mazereeuw J, Barrié L, Nizard S, Bonafé JL, Calvas P, Hovnanian A. Novel ABCC6 mutations in pseudoxanthoma elasticum. J Invest Dermatol 2004; 122: 608-613.

18. Nagamine N, Nohara Y, Ito E. Elastofibroma in Okinawa. A clinicopathologic study of 170 cases. Cancer 1982; 50 1794-1805.

19. Yamazaki K. An ultrastructural and immunohistochemical study of elastofibroma: CD 34, MEF-2, prominin 2 (CD133), and factor XIIIa-positive proliferating fibroblastic stromal cells connected by Cx43-type gap junctions. Ultrastruct Pathol 2007; 31: 209-219.

20. Narvaez D, Kanitakis J, Faure M, Claudy A. Immunohistochemical study of CD34-positive dendritic cells of human dermis. Am J Dermatopathol 1996; 18: 283-288.

21. Silverman, Jeffrey S, Tamsen, Ali. CD34 and Factor XIIIa-Positive Microvascular Dendritic Cells and the Family of Fibrohistiocytic Mesenchymal Tumors. Am J Dermatopathol 1998; 20: 533-536.

22. Gray MH, Trimble CL, Zirn J, McNutt NS, Smoller BR, Varghese M. Relationship of factor XIIIa-positive dermal dendrocytes to Kaposi's sarcoma. Arch Pathol Lab Med 1991; 115: 791-796.

23. Hebda PA, Collins MA, Tharp MD. Mast cell and myofibroblast in wound healing. Dermatol Clin 1993; 11: 685-696.

24. Inoue Y, King TE Jr, Barker E, Daniloff E, Newman LS. Basic fibroblast growth factor and its receptors in idiopathic pulmonary fibrosis and lymphangioleiomyomatosis. Am J Respir Crit Care Med 2002; 166: 765-773.

\section{Address for correspondence}

\section{Funda Tasli MD}

Department of Pathology

Faculty of Medicine

Sifa University

35100 , Bornova

Izmir, Turkey

tel. $+902323434445-1450$

fax: +902322502997

e-mail: fundadr@gmail.com 